Energy confinement and magnetic field generation in the SSPX spheromak

B. Hudson, H. S. McLean, R. D. Wood, E. B. Hooper, D. N. Hill, J. Jayakumar, J. Moller, C. Romero-Talamas, T. A. Casper, L. L. LoDestro, L. D. Pearlstein, J. A. Johnson, III, E. Mezonlin

February 12, 2008

Physics of Plasmas 
This document was prepared as an account of work sponsored by an agency of the United States government. Neither the United States government nor Lawrence Livermore National Security, LLC, nor any of their employees makes any warranty, expressed or implied, or assumes any legal liability or responsibility for the accuracy, completeness, or usefulness of any information, apparatus, product, or process disclosed, or represents that its use would not infringe privately owned rights. Reference herein to any specific commercial product, process, or service by trade name, trademark, manufacturer, or otherwise does not necessarily constitute or imply its endorsement, recommendation, or favoring by the United States government or Lawrence Livermore National Security, LLC. The views and opinions of authors expressed herein do not necessarily state or reflect those of the United States government or Lawrence Livermore National Security, LLC, and shall not be used for advertising or product endorsement purposes. 


\section{Energy confinement and magnetic field generation in the SSPX spheromak}

B. Hudson, ${ }^{\text {a) }}$ H.S. McLean, R. D. Wood, E.B. Hooper, D.N. Hill, J. Jayakumar, J. Moller, C. Romero-Talamás ,T.A. Casper, L.L. LoDestro, L.D. Pearlstein

Lawrence Livermore National Laboratory, Livermore, CA

J.A. Johnson III and E. Mezonlin

Florida A\&M University, Tallahassee, FL

a) Invited speaker. Present address: General Atomics, San Diego, CA, 92121

\section{Abstract}

The Sustained Spheromak Physics Experiment (SSPX) [E.B. Hooper, et. al., Nuclear Fusion, Vol. 39, No. 7] explores the physics of efficient magnetic field buildup and energy confinement, both essential parts of advancing the spheromak concept. Extending the spheromak formation phase increases the efficiency of magnetic field generation with the maximum edge magnetic field for a given injector current (B/I) from $0.65 \mathrm{~T} / \mathrm{MA}$ previously to $0.9 \mathrm{~T} / \mathrm{MA}$. We have achieved the highest electron temperatures $\left(T_{e}\right)$ recorded for a spheromak with $T_{e}>500 \mathrm{eV}$, toroidal magnetic field $\sim 1 \mathrm{~T}$ and toroidal current ( 1 MA) [R.D. Wood, D.N. Hill, H.S. McLean, E.B. Hooper, B.F. Hudson, J.M. Moller, "Improved magnetic field generation efficiency and higher temperature spheromak plasmas," submitted to Physical Review Letters]. Extending the sustainment phase to $>8 \mathrm{~ms}$ extends the period of low magnetic fluctuations $(<1 \%)$ by $50 \%$. The NIMROD 3-D resistive MHD code [C.R. Sovinec, T.A. Gianakon, E.D. Held, S.E. Kruger and D.D. Schnack, The NIMROD Team, Phys. Plasmas 10, 1727 (2003)] reproduces the observed flux amplification $\psi_{\text {pol }} / \psi_{\text {gun }}$. Successive gun pulses are demonstrated to maintain the magnetic field in a quasi-steady state against resistive decay. Initial measurements of neutral particle flux in multi-pulse operation show charge-exchange power loss $<1 \%$ of gun input power and dominantly collisional majority ion heating. The evolution of electron temperature shows a distinct and robust feature of spheromak formation: a hollow-to-peaked $\mathrm{T}_{\mathrm{e}}(\mathrm{r})$ associated with $q \sim 1 / 2$ 


\section{Introduction}

A spheromak [1] plasma is formed by injecting magnetic helicity, $K=\int_{\mathrm{V}} \boldsymbol{A} \bullet \boldsymbol{B} d V$, where $\boldsymbol{A}$ is the magnetic vector potential, into an axisymmetric flux conserver. During injection, the magnetic field lines, bent from the vacuum configuration in the flux conserver and the pinching of the current that drives the injection, reconnect and form closed axisymmetric surfaces. During spheromak formation with a coaxial plasma gun, the current flowing along field lines inside the flux conserver drives an $n=1$ instability on the open flux down the geometric axis (sometimes referred to as the "dough-hook" $[2,3,4]$ mode) which drives magnetic reconnection and builds magnetic field but inhibits the formation of nested magnetic surfaces. If gun current is then reduced below the $n=1$ instability threshold, the plasma evolves close to the so-called "Taylor state"[5] in which the plasma currents and magnetic fields reorganize themselves to reach a minimum energy configuration and axisymmetric flux surfaces form. This configuration is characterized by a flat or nearly flat parallel current profile, $\lambda=\mu_{0} J_{\|} / B=$ constant. Best energy confinement is found for a profile which is slightly peaked on the magnetic axis, resulting in a qprofile which lies in the range $1 / 2<q(\psi)<2 / 3$ except near the separatrix, thereby eliminating low-order rational surfaces in the plasma [9]. An additional consequence of $\lambda \approx$ constant is that it limits the drive for resistive tearing modes, which both take energy from the field itself and leads to stochastic field lines and parallel energy transport. Maintaining current on the open flux also maintains the plasma for an extended period of time and delays the onset of a destructive $n=2$ (toroidal) mode caused by decay of the current near the wall which would lead to a decrease of the safety-factor at the edge below $q=1 / 2$.

One of the most important goals of spheromak research is to understand how to build closed equilibria and sustain a stable discharge long enough for Ohmic heating to heat the 
plasma. Previous work at the CTX spheromak at Los Alamos [6] resulted in temperatures of $>150 \mathrm{eV}$ for driven spheromaks and toroidal currents of $>250 \mathrm{kA}$ in discharges up to $2 \mathrm{~ms}$ in duration. Decaying spheromaks on CTX heated to 400eV[7]. The Sustained Spheromak Physics Experiment [8,9] (SSPX) at Lawrence Livermore National Laboratory, built upon these achievements and has attained electron temperatures of $>500 \mathrm{eV}, \mathrm{I}_{\text {tor }}>1 \mathrm{MA}$, and discharges of 9 ms. [10]

We report on magnetic field generation [11] and energy confinement in the SSPX spheromak. Four operating modes are examined: 1) "extended formation" which we note leads to higher magnetic fields and record electron temperatures [10], 2) "long decay" which maintains the spheromak in stable decay, with duration recently extended from $3.5 \mathrm{~ms}$ to over $8 \mathrm{~ms}, 3$ ) "extended drive" with a flat-top current just slightly above the threshold for building magnetic field [19] that is compared to NIMROD simulations, and 4) "multi-pulse" or "pulsed-reflux," a repetitively pulsed mode [12] that demonstrates quasi-steady-state sustainment of the magnetic field with partial recovery of plasma energy between field-building pulses. These are compared to "Standard" discharges [11] that feature a shorter higher-current formation pulse followed by a lower-current flat-top sustainment pulse.

Several more terms need to be defined in addition to those described above. The efficiency of field build-up and current drive can be described in terms of Flux Amplification and Current Amplification. Flux Amplification $=F A=\psi_{\mathrm{pol}} / \psi_{\mathrm{gun}}$ where $\psi_{\mathrm{pol}}$ is the confined poloidal flux and $\psi_{\text {gun }}$ is the magnetic flux generated by the inner electrode solenoid and bias coils (Fig.1). Current Amplification $=C A=\mathrm{I}_{\text {tor }} / \mathrm{I}_{\text {gun }}$ where $\mathrm{I}_{\mathrm{tor}}=$ toroidal plasma current inside the mean-field separatrix and $\mathrm{I}_{\text {gun }}$ is the discharge current flowing into the gun from the capacitor banks. Since $\psi_{\text {pol }}$ and $\mathrm{I}_{\mathrm{tor}}$ are not directly measured but obtained through equilibrium 
reconstruction with CORSICA, it is useful to describe both $F A$ and $C A$ in terms of experimentally measurable quantities: $\psi_{\text {gun }}, I_{\text {gun }}$, and $B_{\text {edge }}=$ the poloidal magnetic field at the outer edge above the diagnostics slot. $\mathrm{B}_{\text {edge }} / \psi_{\text {gun }}$ can be considered a measure of Flux Amplification since $\psi_{\text {poo }} / \psi_{\text {gun }} \sim 2 \pi R a B_{\text {edge }} / \psi_{\text {gun }} \propto \mathrm{B}_{\text {edge }} / \psi_{\text {gun }}$ where $\mathrm{R}=$ plasma major radius and a $=$ plasma minor radius. $\mathrm{B}_{\text {edge }} / \mathrm{I}_{\text {gun }}$ can be considered a measure of Current Amplification $=\mathrm{I}_{\mathrm{tor}} / \mathrm{I}_{\mathrm{gun}}$ since $\mathrm{I}_{\text {tor }} / \mathrm{I}_{\text {gun }} \propto \mu_{0} \mathrm{I}_{\text {tor }} / 2 \pi a I_{\text {gun }} \sim \mathrm{B}_{\text {edge }} / I_{\text {gun }}$.

For "Standard" discharges, in which the formation gun current is pulsed transiently $(<0.3$ $\mathrm{ms})$, the maximum efficiency of field build-up is limited to $\mathrm{B}_{\text {edge }} / \mathrm{I}_{\text {gun }} \sim 0.65 \mathrm{~T} / \mathrm{MA}[10]$. In discharges where the gun current is kept above the formation threshold for an extended length of time relative to a fast, transient formation pulse, so-called "extended formation", we observe a higher value of $\mathrm{B}_{\text {edge }} / \mathrm{I}_{\text {gun }}=0.9 \mathrm{~T} / \mathrm{MA}[10,11]$. The scaling of maximal electron temperature with the peak magnetic field has been measured to be $T_{e} \sim B^{2}[13,14]$. During "extended formation" pulses, we obtained some of our largest edge fields $\left(B_{p} \sim 0.6 \mathrm{~T}\right)$ and measured electron temperatures via a multi-point Thomson scattering diagnostic, in excess of $500 \mathrm{eV}$, with many discharges in excess of $450 \mathrm{eV}$. By doing equilibrium reconstruction and a power balance with the CORSICA code, we estimate electron thermal transport to be $<10 \mathrm{~m}^{2} / \mathrm{s}$. These highest temperatures are also consistent with earlier results that gave peak temperatures when $q$ over most of the plasma volume was between $1 / 2$ and $2 / 3$, thus low-order rational surfaces were not present for instabilities to grow and degrade confinement. A Thomson scattering scan of similar high-temperature discharges also show a clear and reproducible hollow temperature profile commensurate with the presence of a $q=1 / 2$ surface.

To explore confinement and heating during long duration discharges (i.e. "long-decay") we extended the length of the sustainment phase of the plasma to beyond $8 \mathrm{~ms}$, with enough gun 
current to maintain stability but not enough current to build magnetic field. As a result, the field decays slowly during the discharge and does not terminate abruptly with an $n=2$ instability. To do this, gun current is programmed to decrease at approximately the same rate as the decaying magnetic field. A time-resolved electron temperature scan finds temperatures $>200 \mathrm{eV}$ out to 4.5 ms.

By maintaining a very constant gun current for several milliseconds in the sustainment phase ("extended drive"), the poloidal magnetic flux in the spheromak apparently builds to saturation. Equilibrium reconstruction of the flux surfaces allows comparison with the NIMROD 3-D MHD code and we find that during quiescent plasma conditions NIMROD accurately reproduces the value calculated from experiment.

To address the question of field sustainment we created a train of formation pulses ("pulsed-reflux" sometimes called "multi-pulse"). By varying the separation of the pulses we were able to obtain a quasi-steady state mode of operation where the magnetic field is held against resistive decay for several milliseconds. Thomson scattering measurements were taken every $100 \mu$ s with a second laser pulse coming $40 \mu$ s after the first pulse. We see a loss of plasma heat due to the driven $n=1$ mode in each of these pulses. The mode opens the magnetic field lines and heat is lost due to parallel heat conduction. Electron temperature begins increasing again as the current drops between pulses and flux surface closure improves. Also observed is a reproducible hollow temperature profile again commensurate with the presence of a $q=1 / 2$ surface.

Charge exchange particle energy analyzer measurements taken during multi-pulse operation show that charge-exchange losses are very small compared to the Ohmic power input. 
We also report the first measurements of majority ion temperatures $(\sim 200 \mathrm{eV})$ that imply collisional heating of ions by electrons during the quiescent phase between pulses.

\section{RESULTS AND DISCUSSION}

\section{A. Field Build-Up and Stability}

The traditional mode of spheromak operation is to have a short voltage pulse between the plasma gun anode and cathode, which breaks down the injected gas and ejects the plasma into the flux conserver. The length of this "formation" pulse in the so-called "standard" discharge is on the order of $100 \mu \mathrm{s}$, with the decay of the current set by the particulars of the capacitor bank circuit and the plasma impedance. To explore the limits of field build-up we operate in "extended formation" where instead of a transient peak, the formation current is flat for 400-600 $\mu$ s and more importantly remains above the ejection threshold for up to $1 \mathrm{~ms}$. Figure 2 shows a comparison between a typical extended formation discharge and a standard discharge. Figure 2a shows the gun current, which in the extended discharge exceeds threshold for nearly $1 \mathrm{~ms}$. vs. $0.5 \mathrm{~ms}$ for the standard discharge. Figure $2 \mathrm{~b}$ shows the edge poloidal field, $B_{p}$ as measured by a Rogowski loop near the midplane of the flux conserver. The extended formation discharge continues to build field throughout the entire formation pulse whereas the standard formation discharge ceases building field only $200 \mu$ s into the shot. For gun current a factor of 1.2 higher than the standard formation shot, the field was 1.6 times larger.

We continue to inject helicity, $K$, at a fairly constant rate after the initial rise in gun current, and the flux build-up continues against the helicity decay rate, $d K / d t=2 V_{\text {gun }} \psi_{\text {gun }}-K / d \tau$. By extending the time that we inject helicity, we are able to build to higher magnetic fields because we have not yet approached a limit of field saturation. 
Extended formation shots show larger flux amplification, expressed by $\mathrm{B}_{\text {edge }} / \Psi_{\text {gun }}$, for a given normalized current $\left(\lambda_{\text {gun }}=\mu_{0} \mathrm{I}_{\text {gun }} / \Psi_{\text {gun }}\right)$. Fig. 3 shows the values of $\mathrm{B}_{\text {edge }} / \Psi_{\text {gun }}$ for a large database of standard formation discharges (black points) and extended formation discharges (red points). A detailed study of efficiency (in terms of B versus I and B/I versus $\lambda_{\text {gun }}$ ) which also shows the importance of flux geometry length to diameter ratio is reported by Wood, et. al. in [10].

\section{B. Confinement and Heating in Extended Formation}

At a constant $\beta_{\mathrm{e}}$, we expect electron temperature to scale approximately as $B^{2}$ due to Ohmic heating, until radiative or other loss mechanisms become significant. The importance of being able to build to high field while maintaining low fluctuations to avoid stochastic transport is paramount. During the extended formation campaign we attained our largest magnetic fields and highest edge poloidal magnetic field measurements. Data for several high temperature discharges (with $T_{\mathrm{e}}>400 \mathrm{eV}$ ) are given in Ref. [10] with highest temperatures in SSPX exceeding $500 \mathrm{eV}$.

In order to quantify the confinement of our plasmas, we perform the standard analysis technique of using equilibrium reconstruction (CORSICA) from measured edge fields and the measured electron density and temperature profiles in the steady state power balance, $\nabla \bullet\left(\chi_{e} \nabla\left(n_{e} T_{e}\right)\right)=\eta j^{2}$, in order to calculate value of $\chi_{e}$, the electron thermal diffusivity. We assume radiated power in this analysis is small compared to ohmic power. $T_{e}$ spatial profile data in Fig.4a (plotted versus radius) and $4 \mathrm{~b}$ (plotted versus flux) shows good alignment of $\mathrm{T}_{\mathrm{e}}$ data to CORSICA equilibrium reconstructed flux surfaces both inboard and outboard of the magnetic axis. Good alignment to reconstructed flux surfaces increases confidence in both the reconstruction and the $T_{e}$ measurement. A polynomial fit of $T_{e}$ is used in the power balance 
analysis, fit is shown in Fig. 4a. The on-axis values of $\chi_{\mathrm{e}}$ are shown in Figure 5 for many standard discharges as well as the select high $\mathrm{T}_{\mathrm{e}}$ discharges. As has been previously reported, the calculated $\chi_{\mathrm{e}}$ decreases with increasing $\mathrm{T}_{\mathrm{e}}$. Analysis of the discharges with extended formation yields higher $\chi_{\mathrm{e}}$ than the standard formation discharges would suggest for the given electron temperatures, however $\chi_{\mathrm{e}}$ is still below $10 \mathrm{~m}^{2} / \mathrm{s}$. Density control under many of the extended formation discharges was more difficult. The measured electron density for these shots was $2-3 \times 10^{20} \mathrm{~m}^{-3}$, whereas the standard formation discharges were the nominal value of $1 \times 10^{20}$ $\mathrm{m}^{-3}$. It is likely that this additional density carried with it impurities from the electrodes which

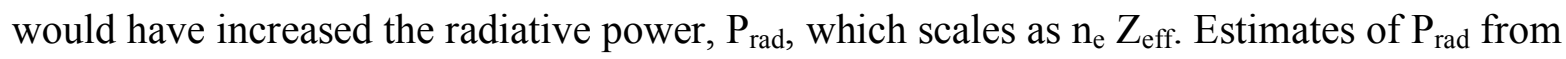
filtered soft x-ray detectors (Fig. 2g) give a very rough (factor of $\sim 2$ ) estimate of radiated power that is larger, compared to $\mathrm{P}_{\mathrm{oh}}=$ ohmic heating power, for these extended formation discharges. Including $P_{\text {rad }}$ in the energy transport power balance would reduce the calculated $\chi_{\mathrm{e}}$ so $10 \mathrm{~m}^{2} / \mathrm{s}$ can be considered an upper bound in this analysis. The energy confinement time, $\tau_{\mathrm{E}}=$ plasma thermal energy $/$ ohmic power $=\mathrm{U}_{\text {therm }} / \mathrm{P}_{\text {oh }}$, integrated over the volume inside the separatrix for the high-temperature extended formation discharges (see Fig. 4) is $\tau_{E} \sim 1 \mathrm{~ms}$ assuming $\mathrm{T}_{\mathrm{i}}=\mathrm{T}_{\mathrm{e}}$. Ohmic power in the cold plasma near the separatrix is large and dominates energy confinement time. Energy confinement in the core is much better; integrating $U_{\text {therm }} / \mathrm{P}_{\text {oh }}$ from the magnetic axis out to $\mathrm{r} / \mathrm{a}=0.5$ gives $\tau_{\mathrm{E}} \sim 10 \mathrm{~ms}$.

Figure 6a shows the results of scanning Thomson scattering measurements during reproducible extended formation discharges. The vertical dashed lines are the times at which the measurements were taken and each measurement is an ensemble average of 3-5 discharges. Figure 6a shows the electron temperature initially flat and cold, then transitioning hollow with a maximal value of about $200 \mathrm{eV}$, followed by a transition to a heating phase where the plasma 
reaches $350 \mathrm{eV}$. Finally the plasma cools as the field decays and the discharge ends. In Figure $6 \mathrm{~b}$ we see the calculated $q$ profile from CORSICA which shows a $q=1 / 2$ surface in the plasma while the temperature profile is hollow, and the maximum heating occurring when the $q=1 / 2$ surface is mostly or completely out of the plasma volume. The observant reader also should note that the $q=1 / 2$ surface returns and with it the hollowing of the temperature at approximately 3.2 ms. Moreover, the maximal heating occurs when $q$ is between $1 / 2$ and $2 / 3$, thus avoiding the presence of low-order rational surfaces in the plasma. This optimal range of $q$ in the context of high temperatures has been previously shown in standard discharges [9].

\section{Long pulse discharges}

Extending the plasma discharge addresses the question of heating and confinement in a plasma characterized by a longer period between formation and the onset of instabilities near the end of a discharge. As shown in Figure $7 \mathrm{a}$ and $7 \mathrm{~b}$, we form a plasma and allow it to decay while keeping the gun current below the threshold for driving $n=1$ kink instabilities. Following the formation phase, the heating phase (Figure 7c) extends up to $4.5 \mathrm{~ms}$, about double that of standard discharges, with peak temperatures around $300 \mathrm{eV}$. The period of steady heat-up and cool-down that we see in standard discharges is also lengthened from about $1 \mathrm{~ms}$ to $3 \mathrm{~ms}$. The $q$ profile of the discharge (Figure 7d) also shows that the highest temperatures are attained when $1 / 2<q<2 / 3$. Moreover, a more optimized run, with the gun current adjusted such that the $2 / 3$ surface wasn't present, would likely have produced either stronger heating, or an extended temperature flat-top, either of which would create unique spheromak plasmas to act as test-beds for future experiments, neutral beam injection in particular. Though not a clear example, we see 
again that there is a hollowing of the temperature profile when the $q=1 / 2$ surface appears in the plasma.

\section{Numerical Simulation of extended drive}

The NIMROD [15] code has been very successful in reproducing much of the key physics observed in SSPX plasmas [16], and further validation studies are ongoing. One of the most important aspects to spheromak plasmas is that the confined flux exceeds the bias flux. Higher Flux Amplification, FA, leads to higher magnetic fields for a given gun flux leading to higher plasma temperatures since $\mathrm{T} \sim \mathrm{B}^{2}[9,10]$. By operating with $\lambda_{\text {gun }} \tilde{>} \lambda_{\mathrm{fc}}=10 \mathrm{~m}^{-1}$, (Figure $8 \mathrm{a}$ ) i.e. slightly above the flux conserver eigenvalue required for a driven spheromak, we inject helicity continuously into the plasma. Turbulent reconnection processes allow current to diffuse inward and, in this case, partially mitigate the resistive decay of the magnetic field. Equilibrium reconstruction with CORSICA is used to calculate the flux surfaces and $F A$ for the experiment. This result is compared to NIMROD simulation [17] (Figure 8b) and we find that after formation the two results are in quantitative agreement [18]. For extended formation discharges, we are able to plot the calculated $F A$ against $\lambda_{\text {gun }}$ for many discharges and find that they also fall along the line predicted from NIMROD (Figure 9). The time resolved shot is not an extended formation discharge but the data point also is near the linear prediction as shown with the larger green data point at $\lambda=11.5 \mathrm{~m}^{-1}$. The flux amplification for the extended discharges with $\lambda_{\text {gun }}>$ $14 \mathrm{~m}^{-1}$ is found to drop below the prediction; these results are presented elsewhere [10]. 


\section{E. Multi-Pulse Operation}

The building of magnetic field and confined flux is a key goal of spheromak research, but we also wish to sustain the field as long as possible. By repeatedly pulsing the coaxial gun [19] (Figure 10a), such that $\lambda_{\text {gun }}>\lambda_{\mathrm{fc}}$ we are able to sustain the equilibrium against resistive decay (Figure 10c). When $\lambda_{\text {gun }}$ is below $10 \mathrm{~m}^{-1}$, the $n=1$ column mode is not being driven (Figure 10b).

The most detailed Thomson scattering scan in an SSPX plasma was performed (Figure 11d) across many highly reproducible multi-pulse discharges. This was facilitated by a recent upgrade to the Thomson scattering system to enable a second laser pulse only $40 \mu$ s following the initial laser pulse. A measurement was taken every $100 \mu \mathrm{s}$, again with a second pulse $40 \mu \mathrm{s}$ later. Each time interval shown is an ensemble of approximately 5 discharges.

After the gun current drops below the threshold for driving the $n=1$ mode, the magnetic fluctuations (Figure 11c) are greatly reduced, thus decreasing radial energy transport along magnetic field lines. During these periods the plasma begins to heat, forming a hollow temperature profile with particularly rapid heating locally around $0.26 \mathrm{~m}$ and $0.42 \mathrm{~m}$. Following a pulse, the fluctuations increase and plasma cools due to transport along open field lines. It should also be noted that again the presence of a $q=1 / 2$ surface (Figure 11e) coincides with the occurrence of a hollow temperature profile. It can clearly be seen that we could sustain this process, simply by extending the available stored energy to pulse the coaxial plasma gun, however the issue of energy confinement needs to be addressed, perhaps by optimizing the pulse train in either amplitude or separation. 


\section{F. Charge-Exchange Losses and Ion Heating}

The recent addition of a Charge-exchange Neutral Particle Analyzer (CNPA) has allowed measurements of charge exchange power losses and given and estimate of the majority ion temperature [20]. Escaping neutrals are collimated and then stripped by passing through neutral hydrogen. These ions are separated spatially by a vertical magnetic field and collected, providing an energy spectrum of the neutral particle flux. We examine the case of a multi-pulse discharge similar to the kind described in the previous section.

The integrated charge exchange power, assuming $4 \pi$ emission from the plasma, is less than $1 \%$ of the estimated Ohmic heating power (Figure 12a). By fitting the tail of the observed spectrum to a Maxwellian distribution, we are able to estimate the peak ion temperature (Figure 12b). We see that the ion temperature increases from $100 \mathrm{eV}$ to nearly $200 \mathrm{eV}$ between each pulse, where the magnetic fluctuations are not being driven. This is reminiscent of increased electron temperature at the corresponding times for multi-pulse discharges where Thomson data was available (see Figure 11). Only one Thomson scattering measurement was available for this discharge, however, we use a soft x-ray ratio diagnostic (Figure 12c) to estimate electron temperature in the range of $100-300 \mathrm{eV}$, with a strong correlation when $\mathrm{T}_{\mathrm{e}}<200 \mathrm{eV}$. This gives us a proxy time-resolved measurement of peak electron temperature. The electron-ion equilibration time at a density of $10^{14} \mathrm{~cm}^{-3}$ and $T_{e} \sim T_{i}=100 \mathrm{eV}$ gives $\tau_{\mathrm{e} / \mathrm{i}}=0.26 \mathrm{~ms}$. This implies that the electron and ion temperatures track each other closely between pulses, as observed, though with a slight lag in the ion temperature, as would be expected with a small but finite equilibration time. We note that the close tracking of $T_{i}$ to $T_{e}$ implies that in these shots anomalous ion heating is weak or absent, except at the initial formation phase. If this trend is 
shown to remain for other kinds of discharges in spheromak plasmas, it would greatly simplify transport calculations for both electrons and ions.

\section{Summary}

SSPX has achieved plasmas with $T_{e}>500 \mathrm{eV}$ with a peak toroidal plasma current of $>1$ MA and edge poloidal fields $>0.6 \mathrm{~T}$. This was made possible by increased understanding of field generation physics and extending the plasma formation phase. This was observed to build field not just to higher magnitudes but also more efficiently as quantified by $\mathrm{B}_{\mathrm{p}} / \mathrm{I}_{\mathrm{gun}}$. The high magnetic fields in extended formation discharges resulted in electron temperatures routinely with $\mathrm{T}_{\mathrm{e}}>400 \mathrm{eV}$ and a maximum temperature of $525 \mathrm{eV}$. Confinement remained good for these discharges with $<10 \mathrm{~m}^{2} / \mathrm{s}$, but anomalously exceeded the confinement scaling found in standard formation. Long pulse discharges showed an extended heating phase, which could be optimized and favorable for neutral beam experiments. Multi-pulse discharges were explored to test the limits of confinement and field sustainment. The confined magnetic flux was held at a steadystate value though each successive pulse resulted in much of the electron energy being lost. Throughout all observed discharges, a hollow temperature profile is observed when the $q=1 / 2$ surface is present in the plasma, though the causal relationship remains an open question. Finally, neutral particle power loss during multi-pulse operation was shown to be minimal. Majority ion temperatures were measured and found to be closely tied to the electrons, in accordance with the very short ion-electron equilibration time in SSPX.

The authors would like to thank the SSPX group for their input and support and also stress the need for future work to address outstanding key spheromak physics towards the 
spheromak's potential as a fusion concept, particularly with neutral beams to study energy confinement.

\section{Acknowledgment}

Prepared by LLNL in part under contract W-7405-Eng-48 and in part under Contract DEAC52-07NA27344 


\section{References}

[1] M. N. Rosenbluth and M. N. Bussac, Nucl. Fusion 19, 489 (1979)

[2] L. Lindberg and C. Jacobson, Astrophys. J. 133, 1043 (1961)

[3] R. Duck, P. K. Browning, G. Cunningham, S. J. Gee, A. al-Karkhy, R. Martin and M. G. Rusbridge, Plasma Phys. Controlled Fusion 39, 715 (1997)

[4] P. K. Browning, S. J. Gee, K. J. Gibson, A. al-Karkhy, D. A. Kitson, R. Martin and M. G. Rusbridge, Phys. Rev. Lett. 68, 1718 (1992)

[5] J. B. Taylor, Phys. Rev. Lett. 33, 1139 (1974)

[6] F. J. Wysocki, J. C. Fernandez, I. Henins, T. R. Jarboe and G. J. Marklin, Phys. Rev. Lett. 65, 1, 40-41 (1990)

[7] T.R. Jarboe, F.J. Wysocki, J.C. Fernandez, I. Henins, G.J. Marklin, Phys. Fliuds B 2, 1342 (1990)

[8] H. S. McLean, S. Woodruff, E. B. Hooper, R. H. Bulmer, D. N. Hill, C. Holcomb, J. Moller, B. W. Stallard, R. D. Wood, and Z. Wang, Phys. Rev. Lett. 88, 125004 (2002)

[9] H.S. McLean, R. D. Wood, B. I. Cohen, E. B. Hooper, D. N. Hill, J. M. Moller, C. Romero-Talamas and S. Woodruff, Phys. Plasmas, 13, 056105, (2006)

[10] R.D. Wood, D. N. Hill, H. S. McLean, E. B. Hooper, B. F. Hudson, J. M. Moller, "Improved magnetic field generation efficiency and higher temperature spheromak plasmas," submitted to Physical Review Letters.

[11] S. Woodruff, B.I. Cohen, E.B. Hooper, H.S. McLean, B.W. Stallard, D.N. Hill, and C.T. Holcomb, C. A. Romero-Talamás, R.D. Wood, G. Cone and C.R. Sovinec, Phys. Plasmas, 12, 052502, (2005).

[12] S. Woodruff, B.W. Stallard, H.S. McLean, E. B. Hooper, R. Bulmer, B. I. Cohen, D.N. Hill, C.T. Holcomb, J. Moller, and R. D. Wood, Phys. Rev. Letters 93, 205002 (2004).

[13] H.S. McLean, S. Woodruff, D.N. Hill, R.H. Bulmer, B.I Cohen, E.B. Hooper, J. Moller, D.D. Ryutov, B.W. Stallard, R.D. Wood, C.T. Holcomb, T.R. Jarboe, C. Romero-Talamás, P.M. Bellan, Contributed Papers, 30th EPS Conference on Contr. Fusion and Plasma Phys., St. Petersburg, Russia, 7-11 July 2003, Edited by R. Koch, S. Lebedev, (European Physical Society, 2003) Europhysics Conference Abstracts Vol. 27A, P-3.230. Available online at http://epsppd.epfl.ch/StPetersburg/start.html

[14] R.D. Wood, B.I. Cohen, D.N. Hill, E.B. Hooper, R.H. Cohen, S. Woodruff, H.S. McLean, L.L. LoDestro, L.D. Pearlstein, D.D. Ryutov, B.W. Stallard, M.V. Umansky, C.R. Sovinec and G.A. Cone, Nucl. Fusion 45, 1582 (2005). 
[15] C. R. Sovinec, T. A. Gianakon, E. D. Held, S. E. Kruger and D. D. Schnack, The NIMROD Team, Phys. Plasmas 10, 1727 (2003)

[16] B. I. Cohen, E. B. Hooper, R. H. Cohen, D. N. Hill, H. S. McLean, R. D. Wood, and S. Woodruff, C. R. Sovinec and G. A. Cone, Phys. Plasmas 12, 056106 (2005).

[17] E.B. Hooper, B. I. Cohen, D. N. Hill, L. L. LoDestro, H. S. McLean, C. A. RomeroTalamás, R. D. Wood, and C. R. Sovinec, J. Fusion Energy 26, 71 (2007).

[18] E.B. Hooper, D. N. Hill, H. S. McLean, C. A. Romero-Talamás, and R. D. Wood, Nucl. Fusion 47, 1064 (2007).

[19] S. Woodruff, D. N. Hill, B. W. Stallard, R. Bulmer, B. Cohen, C.T. Holcomb, E. B. Hooper, H. S. McLean, J. Moller, R. D. Wood, Phys. Rev. Letters 90, 095001 (2003).

[20] E.D. Mezonlin, S. Roberson, C. Raynor, R. Appartaim, J. A. Johnson, V. I. Afanasyev, S. S. Kozlovsky, J. M. Moller, D. N. Hill, E. B. Hooper, H. S. McLean, and R. D. Wood, Rev. Sci. Instrum. 78, 05350 (2007). 


\section{Figure Captions}

FIG. 1. (Color online) Cross-sectional view of SSPX showing bias coils and reconstruction of spheromak equilibrium flux surfaces. The flux conserver is $1 \mathrm{~m}$ in diameter.

FIG. 2. (Color online) Comparison of standard (black) and extended formation (red) discharges. a) Gun current with extended formation phase. b) Increased magnetic field buildup.

FIG. 3. (Color online) Maximal poloidal edge fields vs. peak gun current. Standard discharges (black) build field at a maximum rate of $0.65 \mathrm{~T} / \mathrm{MA}$, extended formation (red) attain $0.85 \mathrm{~T} / \mathrm{MA}$.

FIG. 4. (Color online) Record $\mathrm{T}_{\mathrm{e}}$ obtained during extended formation.

FIG. 5. (Color online) Electron thermal diffusivity. Standard discharges (black) steadily decrease with increasing $\mathrm{T}_{\mathrm{e}}$, extended formation discharges are anomalously larger than standard discharge scaling.

FIG. 6. (Color online) a) $\mathrm{T}_{\mathrm{e}}$ during extended formation, dashed lines are measurement times. b) Peak $\mathrm{T}_{\mathrm{e}}$ when $1 / 2$ and $2 / 3$ are not in plasma. Contours of $q=1 / 2$ are shown. Hollow when $q \sim 1 / 2$.

FIG. 7. Long pulse discharge. a) Gun current for standard (black) and long pulse (red). Both are not driven during sustainment phase. b) Magnetic field in standard (black) and long pulse (red) is doubled in duration. c) Electron temperature. Heating phase lengthened nearly $2 x$ standard discharges. d) Safety factor. Maximum $\mathrm{T}_{\mathrm{e}}$ occurs when $1 / 2<\mathrm{q}<2 / 3$ and hollow $\mathrm{T}_{\mathrm{e}}$ when $\mathrm{q} \sim 1 / 2$.

FIG. 8. (Color online) Time-dependent flux amplification reproduced by NIMROD. a) Constant current above flux conserver eigenvalue, $\lambda=9.9 \mathrm{~m}^{-1}$. b) Flux amplification from equilibrium reconstruction (red) vs. NIMROD (blue) and a single point analyzed with a Bessel function model.

FIG. 9. (Color online) Comparison of NIMROD (blue line) and Bessel function model (red points) for flux amplification. The data point analyzed in Figure 8 is shown in green.

FIG. 10. (Color online) Field regeneration multi-pulse operation. a) Gun current. b) Gun voltage. c) Edge $\mathrm{B}_{\mathrm{p}}$ maintained in quasi-steady state.

FIG. 11. (Color online) Electron transport during multi-pulse operation. a) Gun current. b) Gun voltage. Low when not driven. c) Magnetic fluctuations. d) $\mathrm{T}_{\mathrm{e}}$ scan. e) Safety factor. Hollow $\mathrm{T}_{\mathrm{e}}$ where $\mathrm{q} \sim 1 / 2$.

FIG. 12. (Color online) Neutral particle analyzer data. a) Charge-exchange power loss is $<1 \%$ of Ohmic power. b) Estimate of majority ion temperature during multi-pulse operation. c) Soft X-Ray signal and corresponding $\mathrm{T}_{\mathrm{e}}$. 
Figures
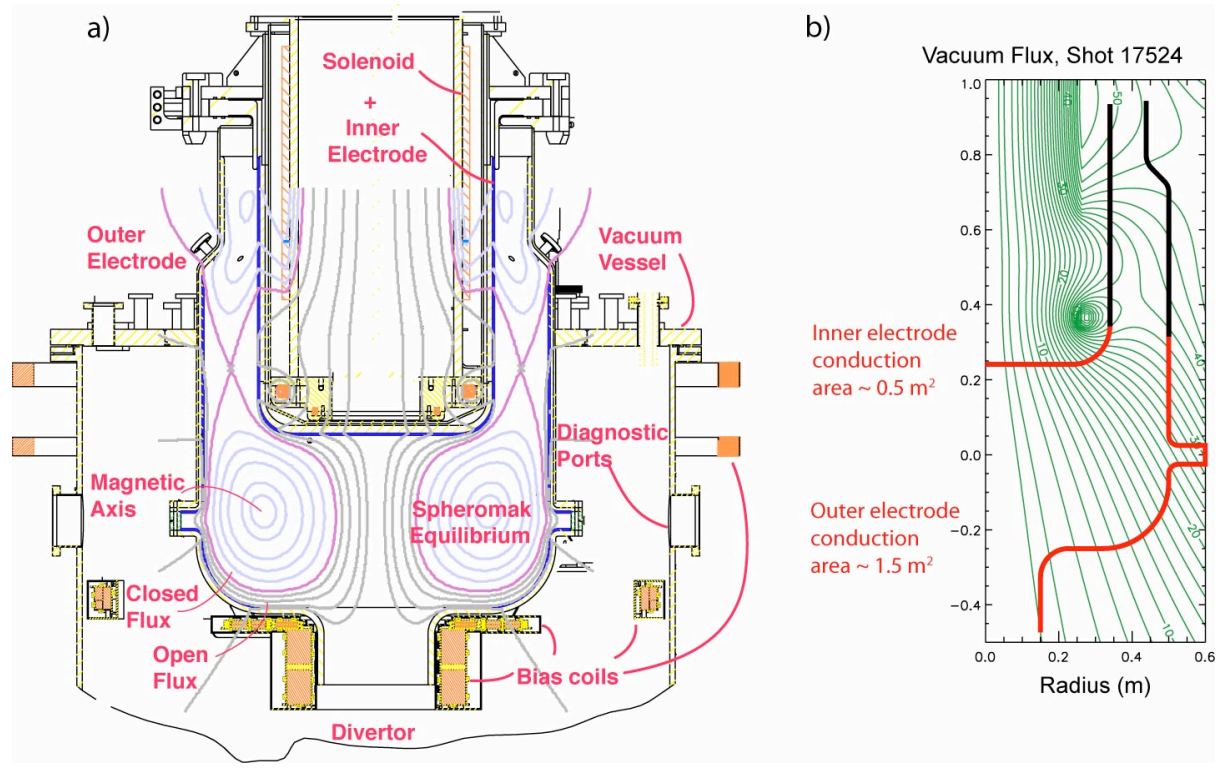

FIG. 1. (Color online) a) Cross-sectional view of SSPX showing bias coils and CORSICA reconstruction of spheromak equilibrium flux surfaces. The flux conserver is $1 \mathrm{~m}$ in diameter. Magnetic flux (light gray lines) penetrates inner and outer electrodes and stays pinned during the discharge.

Separatrix is shown in violet. $\mathrm{I}_{\text {gun }}$ is assumed to flow on these open flux lines with a constant $\lambda_{\text {gun }}=\mu_{0} \mathrm{I}_{\text {gun }} / \Psi_{\text {gun }} . \Psi_{\text {gun }}$ is assumed constant during a discharge and can be varied up to a maximum of $\sim 70 \mathrm{mWb}$. b) Distribution of $\Psi_{\text {gun }}$ prior to discharge for shot $17524\left(\Psi_{\text {gun }} \sim 50 \mathrm{mWb}\right)$ along with estimates of inner and outer electrode current flow areas. 


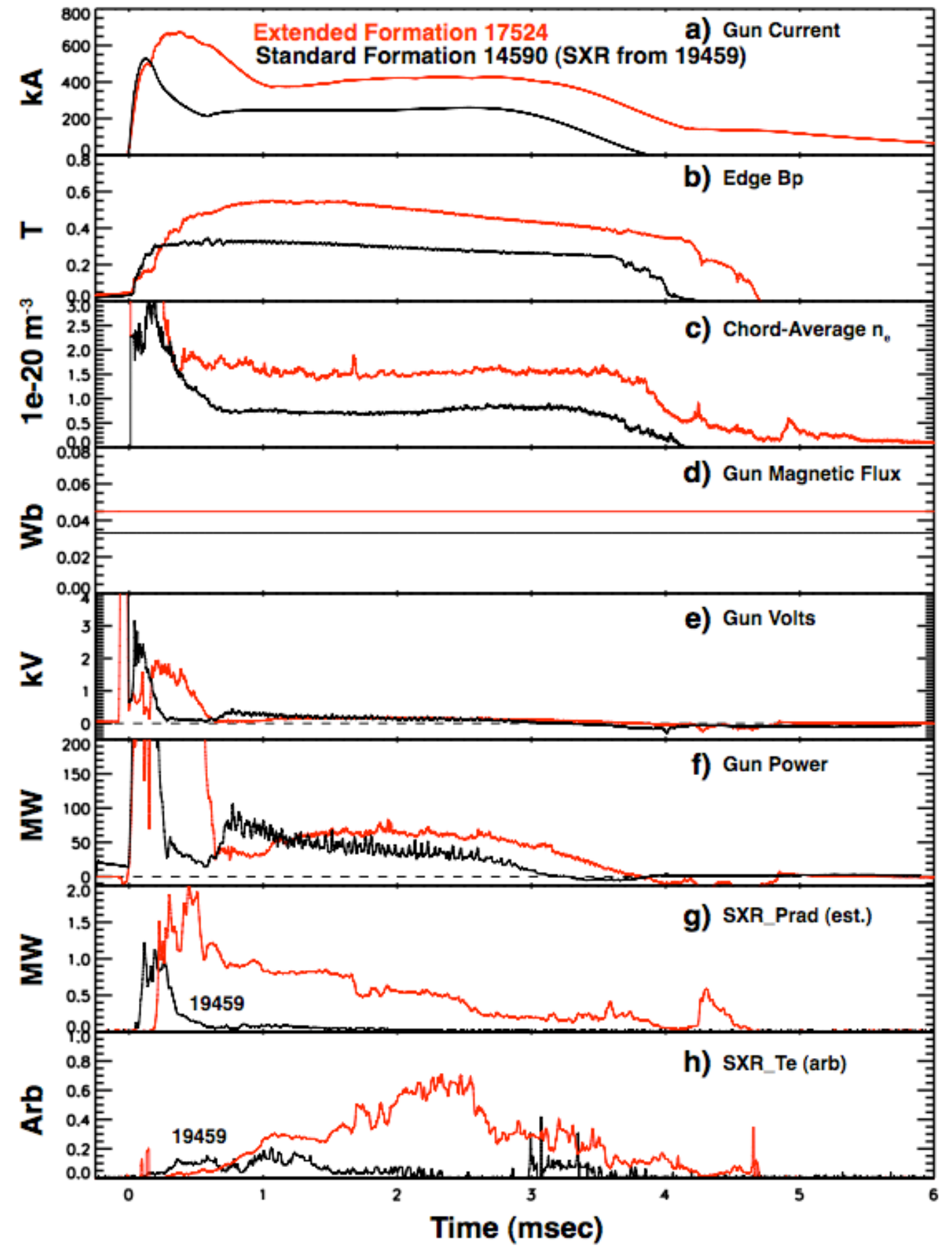

FIG. 2. (Color online) Comparison of standard (black) and extended formation (red) discharges. a) Gun current with extended formation phase. b) Increased magnetic field buildup. 


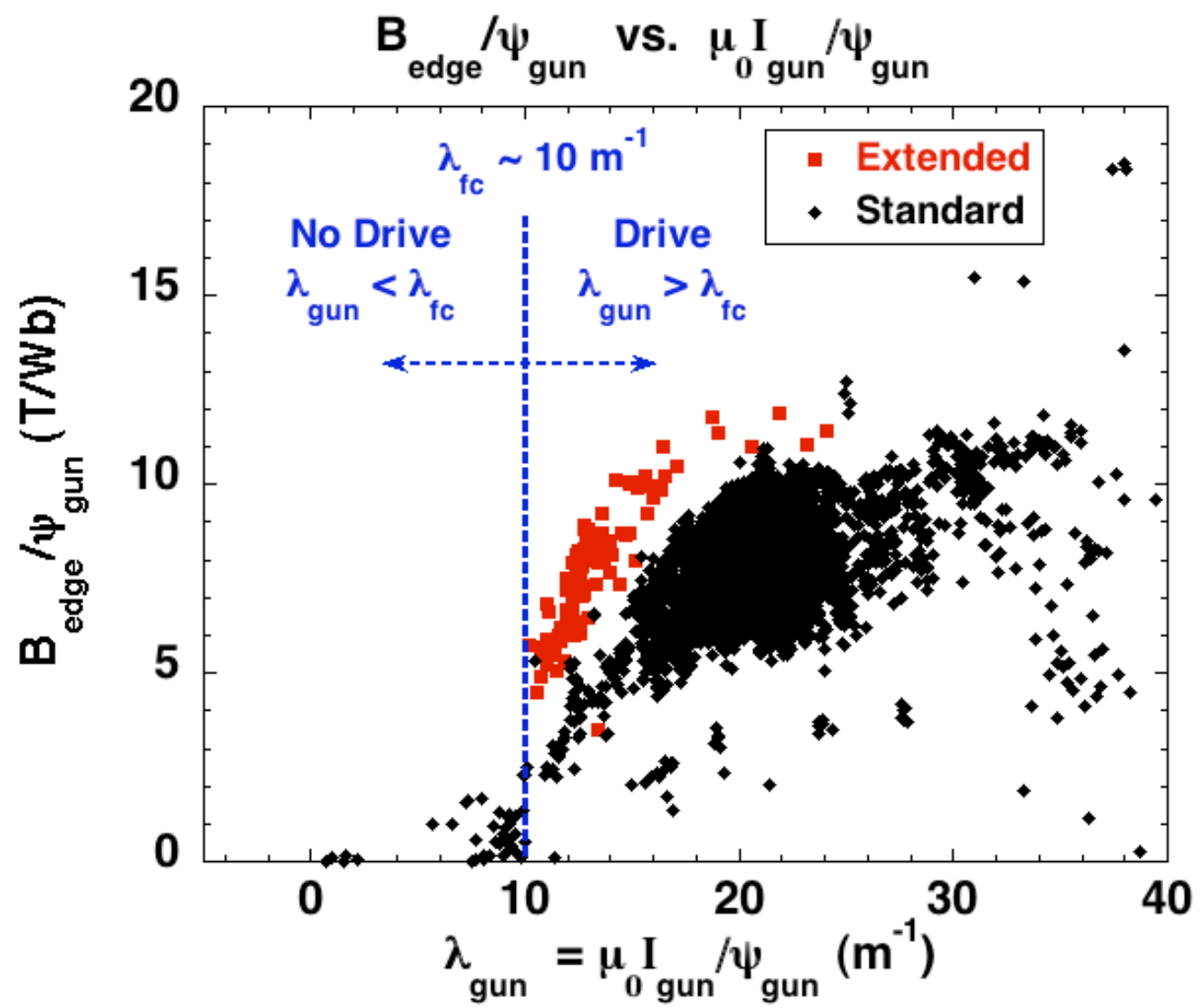

FIG. 3. (Color online) Extended formation shots show larger magnetic field for given gun current and larger flux amplification ( $\left.\mathrm{B}_{\text {edge }} / \psi_{\text {gun }}\right)$ for a given normalized current $\left(\lambda_{\text {gun }}=\mu_{0} \mathrm{I}_{\text {gun }} / \Psi_{\text {gun }}\right)$.
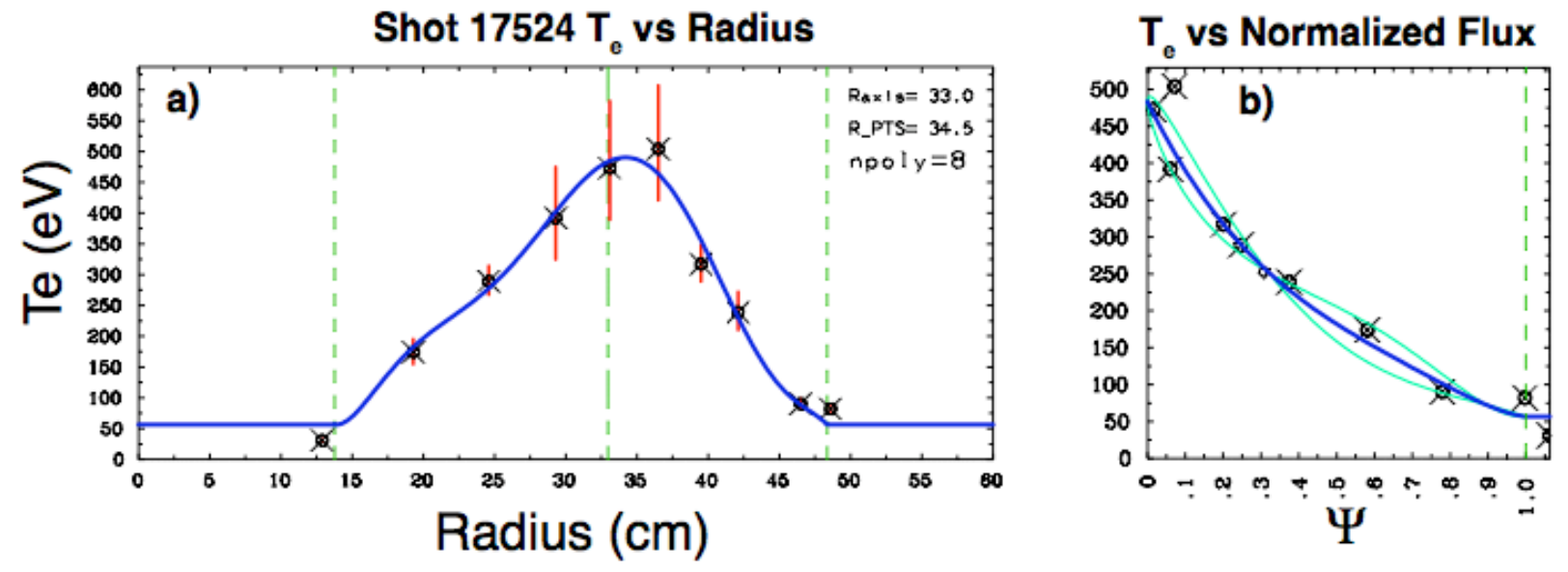
Fig. 4 (color online) a) Polynomial fit of $T_{e}$ to Thomson scattering data used in calculation of $\left.\chi_{e} \cdot b\right) T_{e}$ data shows good alignment of $T_{e}$ to CORSICA equilibrium reconstructed flux surfaces both inboard and outboard of the magnetic axis. 


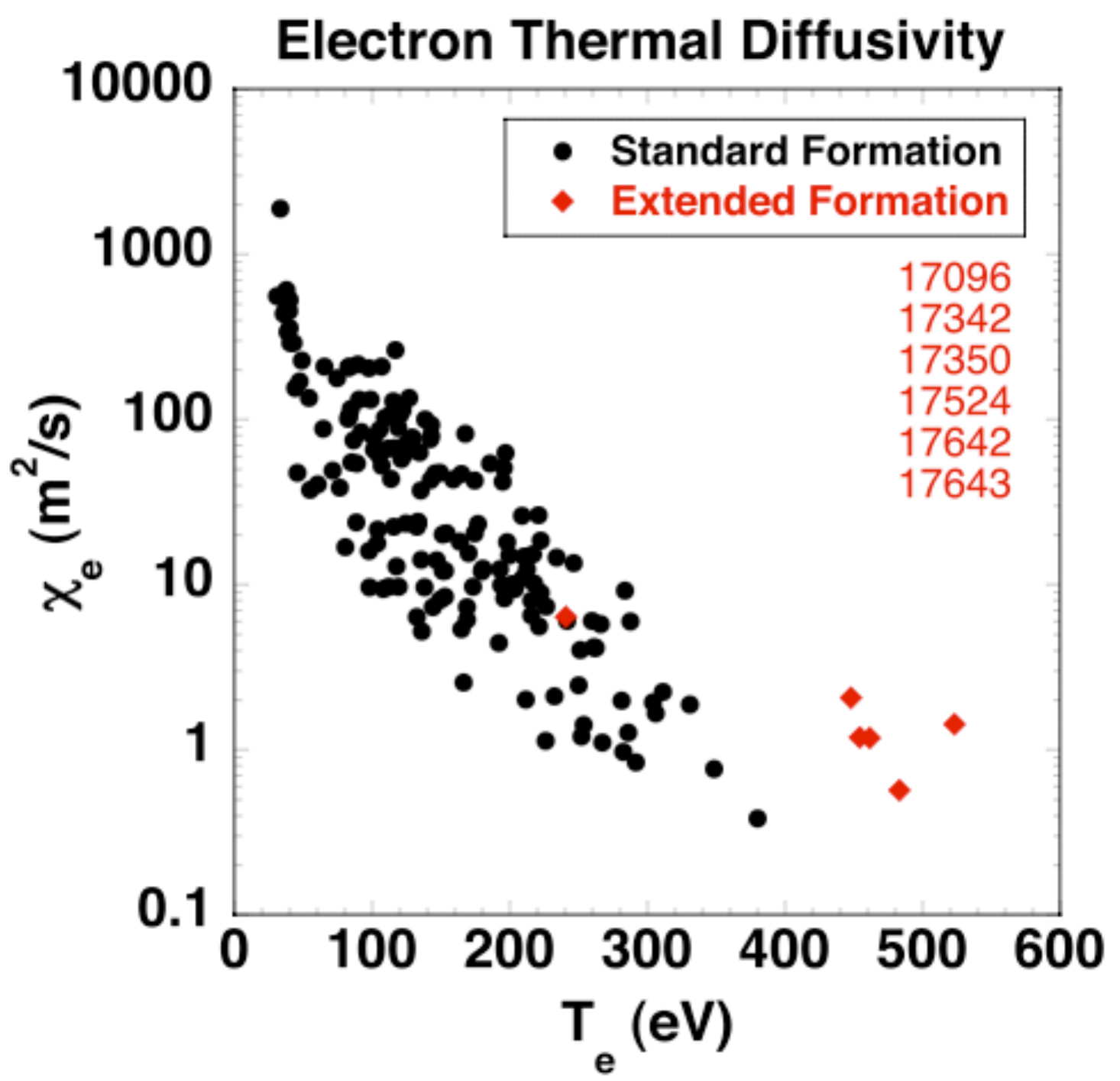

FIG. 5. (Color online) Electron thermal diffusivity. Standard discharges (black) steadily decrease with increasing $\mathrm{T}_{\mathrm{e}}$, extended formation discharges are anomalously larger than standard discharge scaling. 


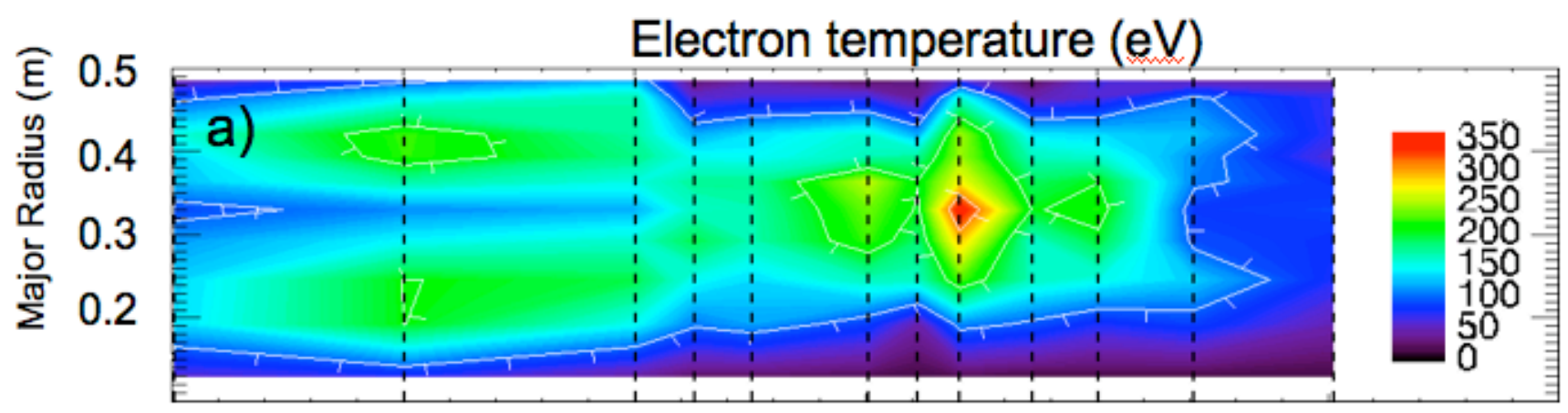

Safety Factor (CORSICA)

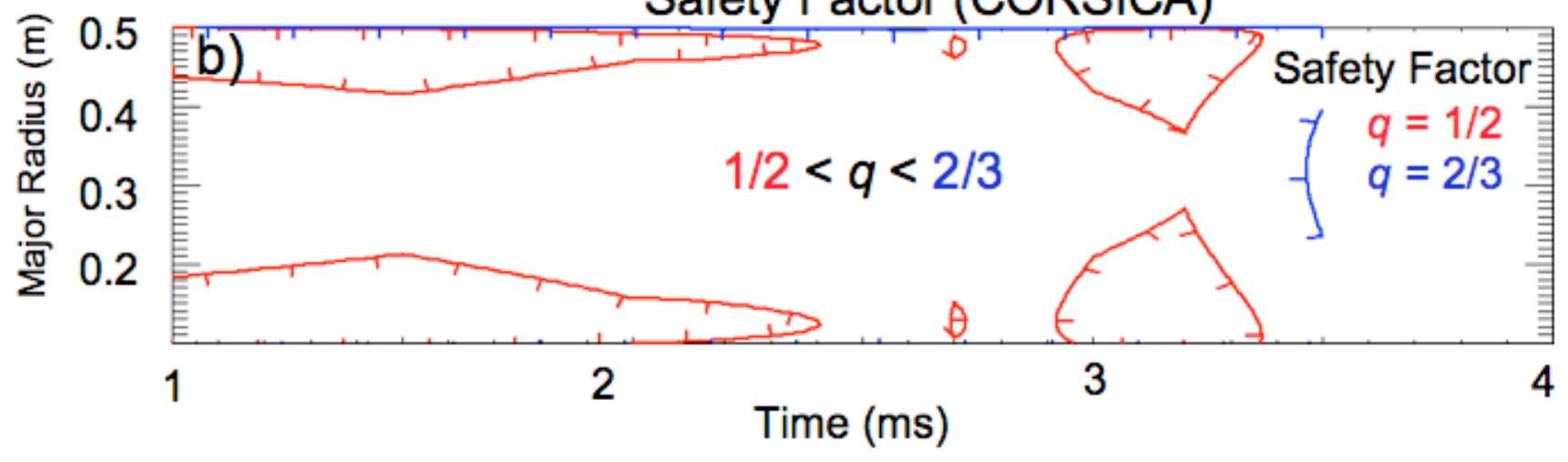

FIG. 6. (Color online) a) $\mathrm{T}_{\mathrm{e}}$ during extended formation, dashed lines are measurement times. b) Peak $\mathrm{T}_{\mathrm{e}}$ when $1 / 2$ and $2 / 3$ are not in plasma. Contours of $q=1 / 2$ are shown. Hollow when $q \sim 1 / 2$ 


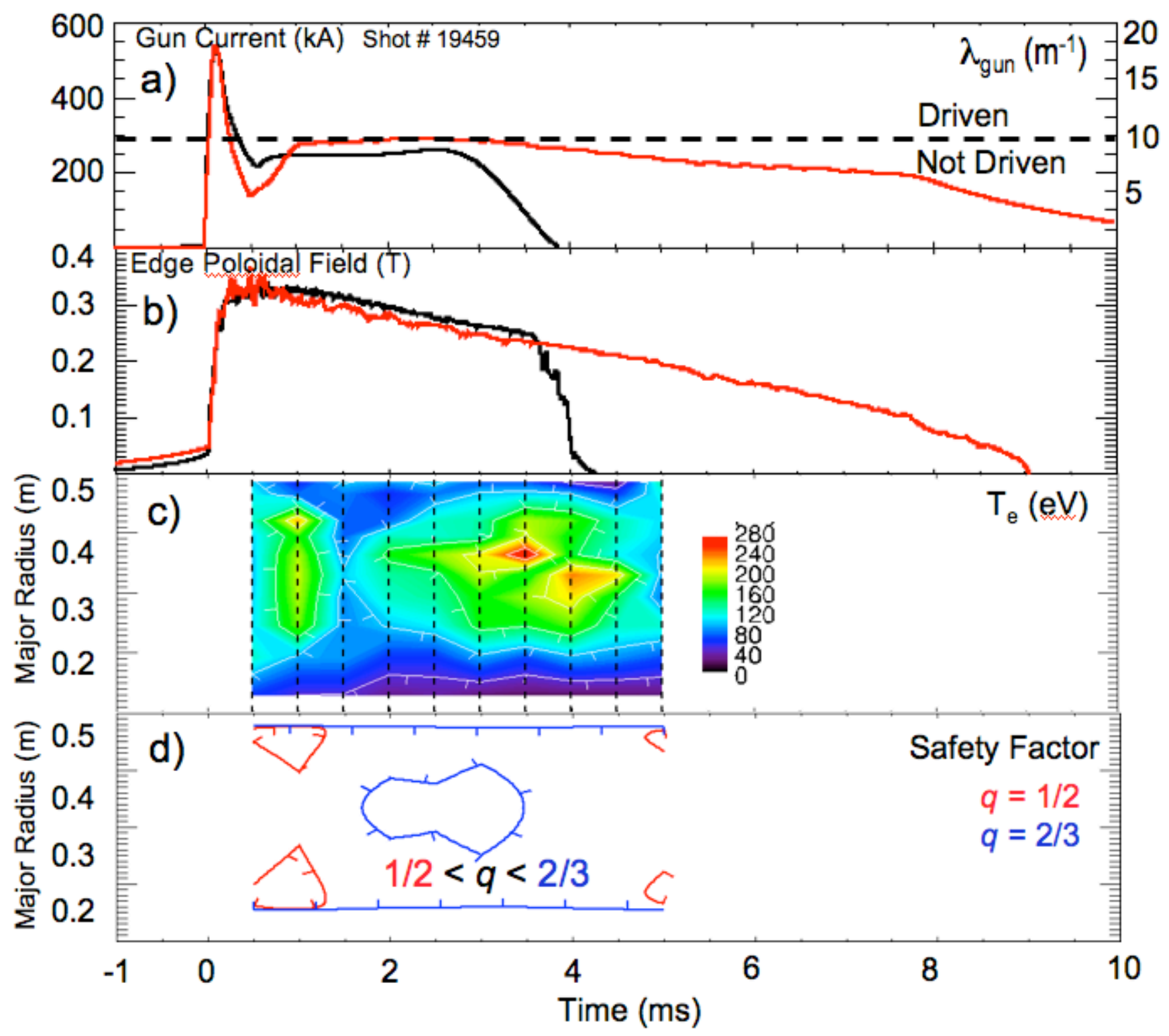

FIG. 7. Long pulse discharge. a) Gun current for standard (black) and long pulse (red). Both are not driven during sustainment phase. b) Magnetic field in standard (black) and long pulse (red) is doubled in duration. c) Electron temperature. Heating phase lengthened nearly $2 x$ standard discharges. d) Safety factor. Maximum $\mathrm{T}_{\mathrm{e}}$ occurs when $1 / 2<\mathrm{q}<2 / 3$ and hollow $\mathrm{T}_{\mathrm{e}}$ when $\mathrm{q} \sim 1 / 2$. 


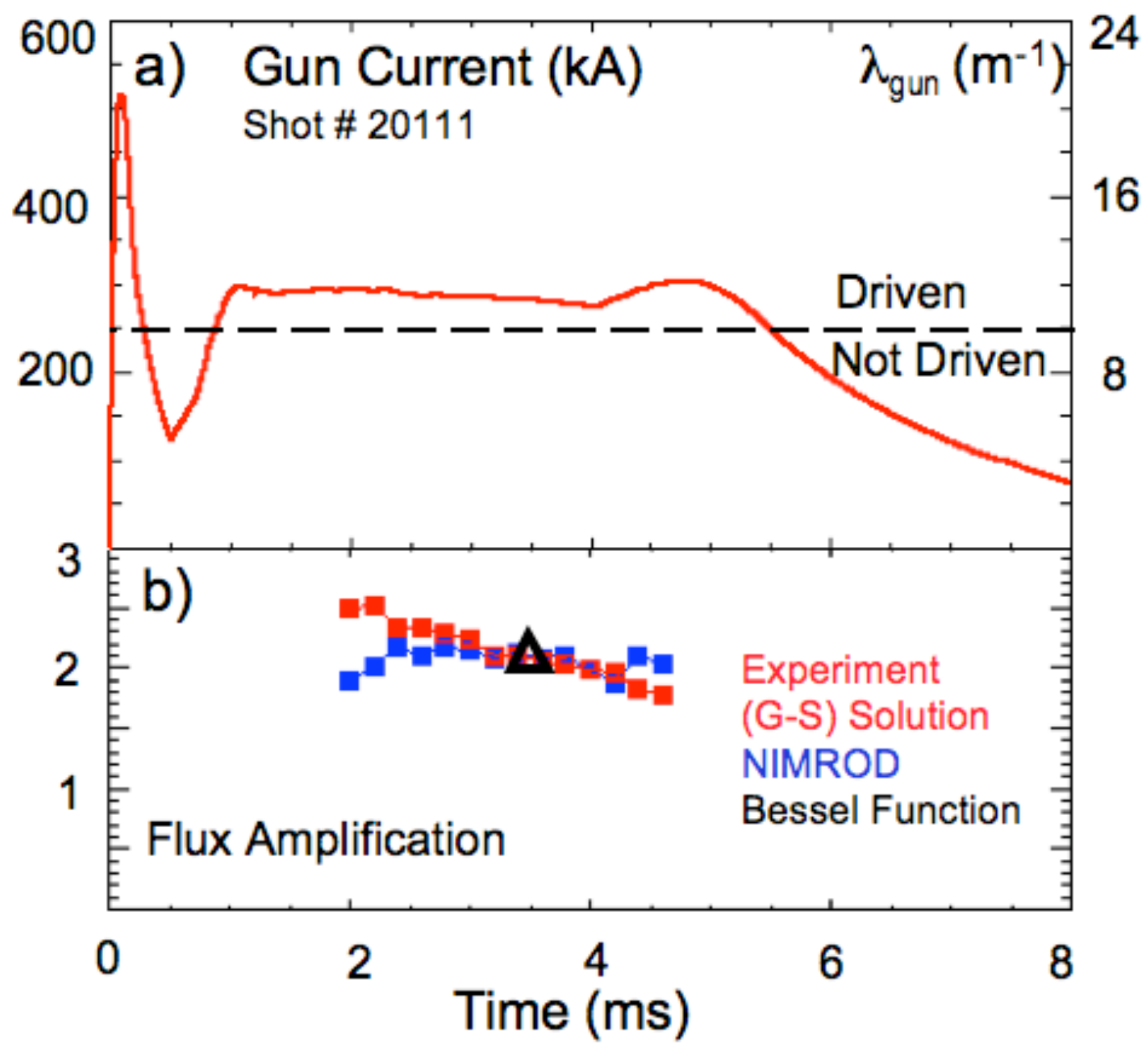

FIG. 8. (Color online) Time-dependent flux amplification reproduced by NIMROD. a) Constant current above flux conserver eigenvalue, $\lambda=9.9 \mathrm{~m}^{-1}$. b) Flux amplification from equilibrium reconstruction (red) vs. NIMROD (blue) and a single point analyzed with a Bessel function model. 
Flux Amplification

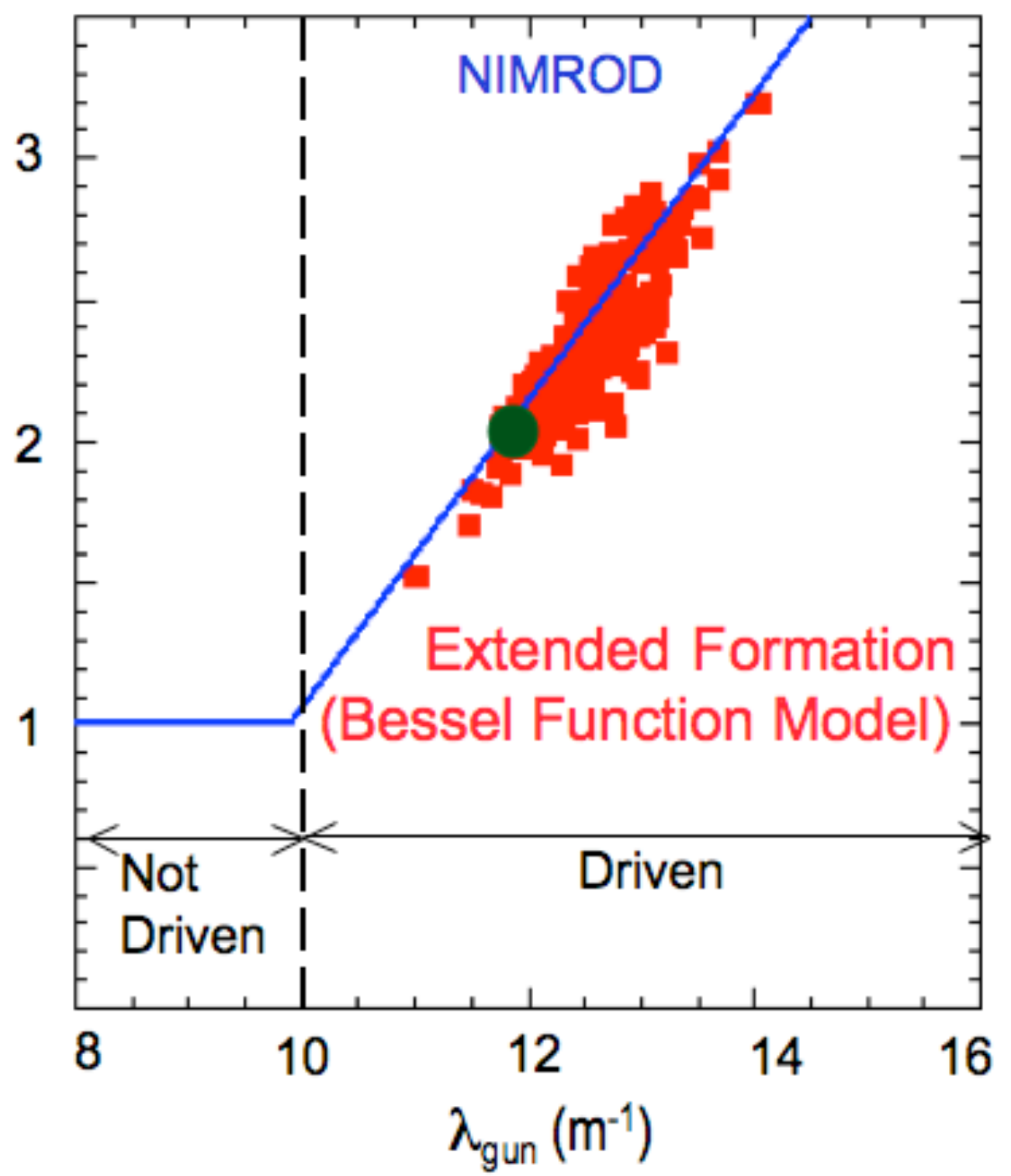

FIG. 9. (Color online) Comparison of NIMROD (blue line) and Bessel function model (red points) for flux amplification. The data point analyzed in Figure 8 is shown in green. 


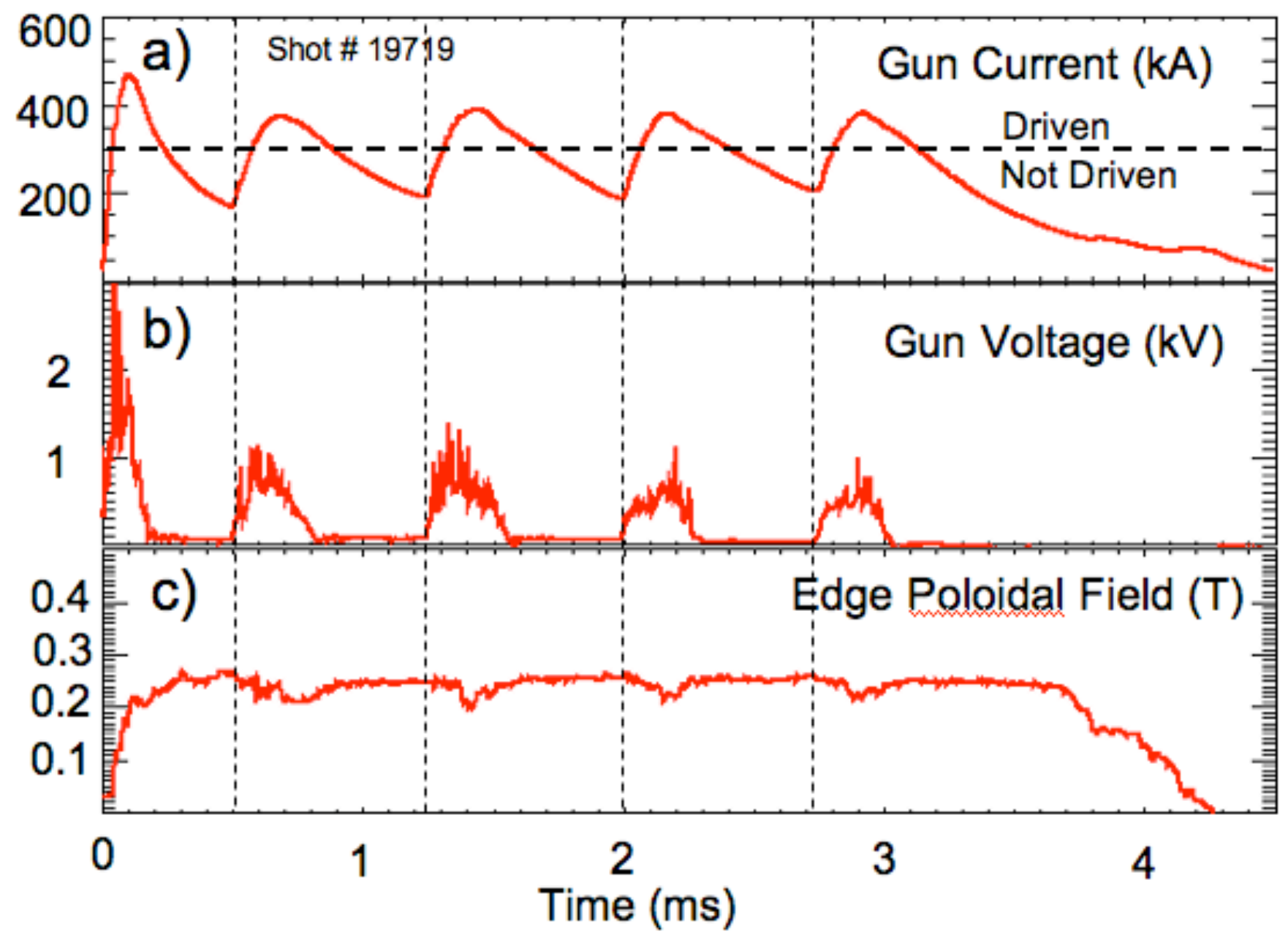

FIG. 10. (Color online) Field regeneration multi-pulse operation. a) Gun current. b) Gun voltage. c) Edge $B_{p}$ maintained in quasi-steady state. 


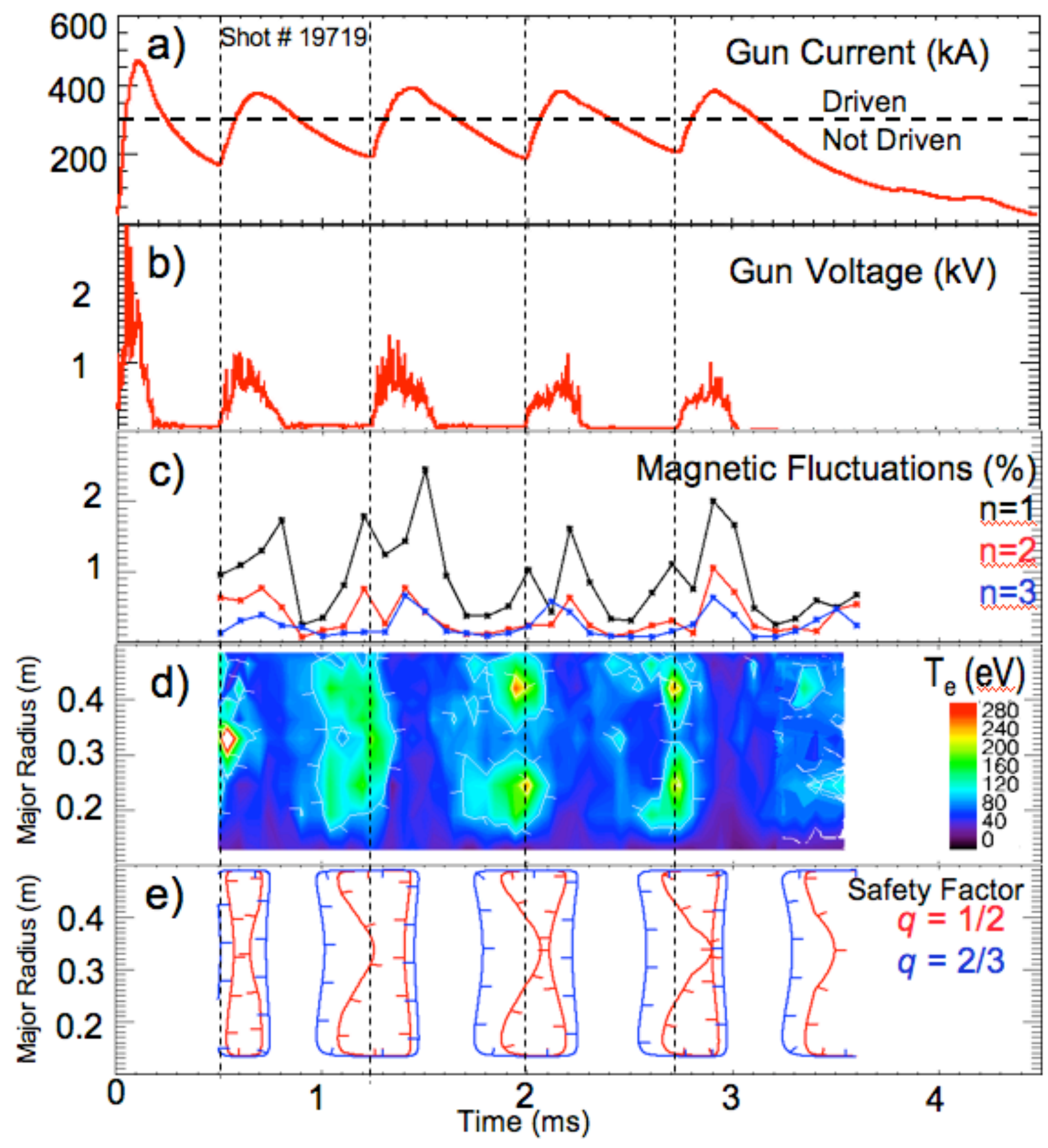

FIG. 11. (Color online) Electron transport during multi-pulse operation. a) Gun current. b) Gun voltage. Low when not driven. c) Magnetic fluctuations. d) $T_{e}$ scan. e) Safety factor. Hollow $T_{e}$ where $\mathrm{q} \sim 1 / 2$. 


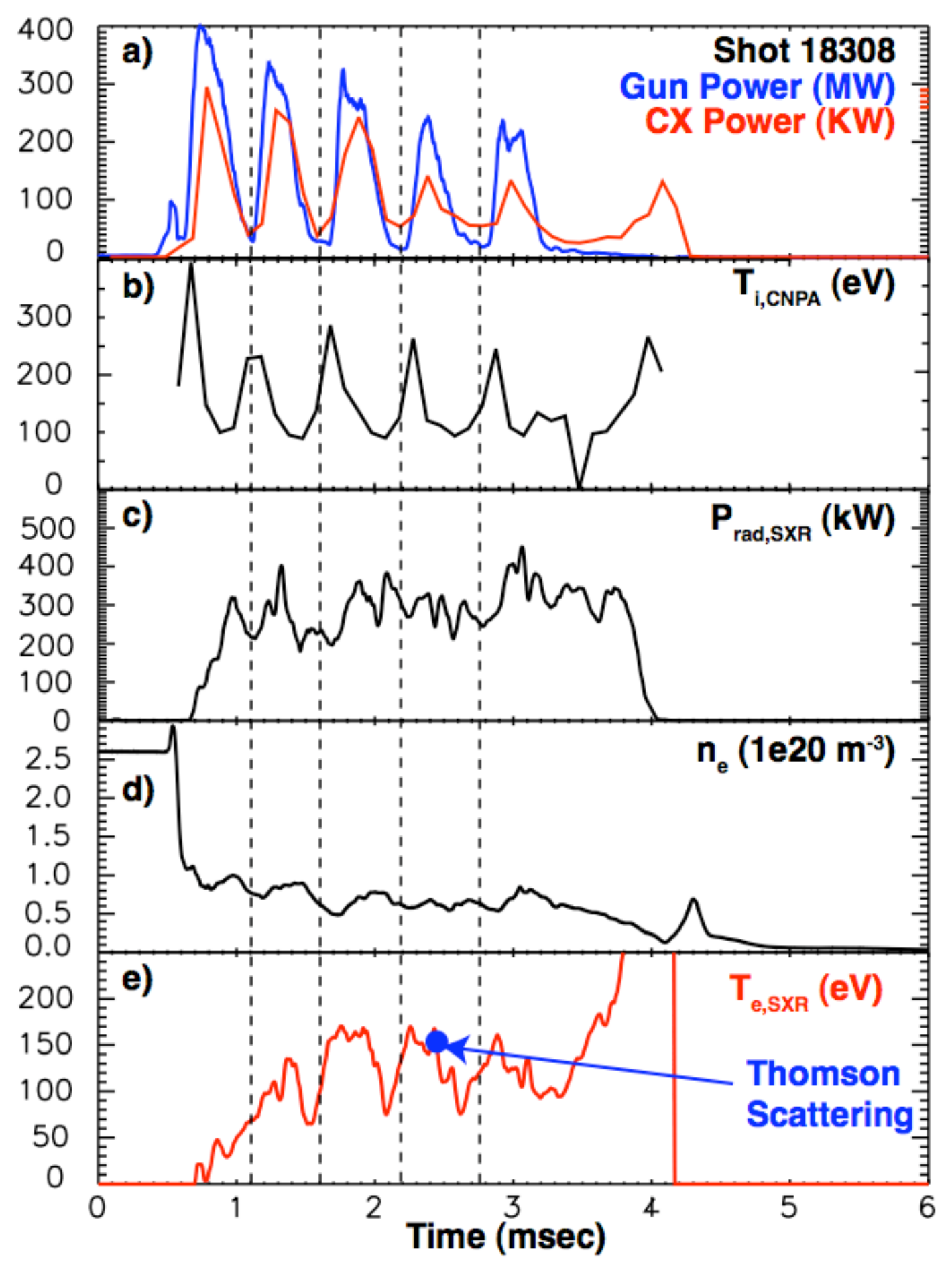

FIG. 12. (Color online) Neutral particle analyzer data. a) Charge-exchange power loss is $<1 \%$ of Ohmic power. b) Estimate of majority ion temperature during multi-pulse operation. c) Soft X-Ray signal and corresponding $\mathrm{T}_{\mathrm{e}}$. 